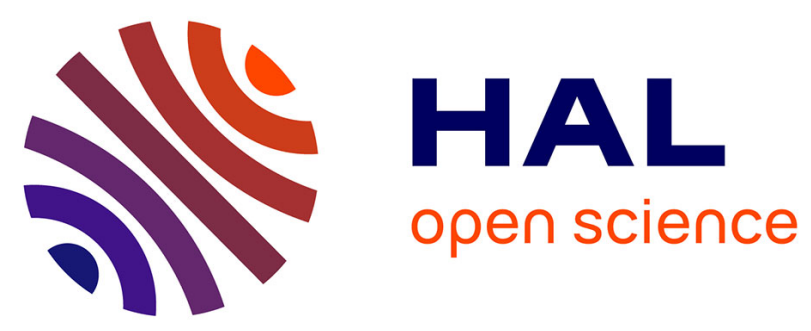

\title{
Opening wedge high tibial osteotomy allows better outcomes than unicompartmental knee arthroplasty in patients expecting to return to impact sports
}

Christophe Jacquet, Firat Gulagaci, Axel Schmidt, Aniruddha Pendse, Sebastien Parratte, Jean-Noël Argenson, Matthieu Ollivier

\section{To cite this version:}

Christophe Jacquet, Firat Gulagaci, Axel Schmidt, Aniruddha Pendse, Sebastien Parratte, et al.. Opening wedge high tibial osteotomy allows better outcomes than unicompartmental knee arthroplasty in patients expecting to return to impact sports. Knee Surgery, Sports Traumatology, Arthroscopy, 2020, 28 (12), pp.3849-3857. 10.1007/s00167-020-05857-1 . hal-03175934

\author{
HAL Id: hal-03175934 \\ https://hal.science/hal-03175934
}

Submitted on 15 Apr 2021

HAL is a multi-disciplinary open access archive for the deposit and dissemination of scientific research documents, whether they are published or not. The documents may come from teaching and research institutions in France or abroad, or from public or private research centers.
L'archive ouverte pluridisciplinaire HAL, est destinée au dépôt et à la diffusion de documents scientifiques de niveau recherche, publiés ou non, émanant des établissements d'enseignement et de recherche français ou étrangers, des laboratoires publics ou privés. 


\title{
Opening wedge high tibial osteotomy allows better outcomes than unicompartmental knee arthroplasty in patients expecting to return to impact sports
}

\author{
Christophe Jacquet ${ }^{1} \cdot$ Firat Gulagaci $^{1}$ - Axel Schmidt ${ }^{1}$. Aniruddha Pendse ${ }^{1}$. Sebastien Parratte ${ }^{2}$. \\ Jean-Noel Argenson ${ }^{1} \cdot$ Matthieu Ollivier ${ }^{1}$
}

\begin{abstract}
Purpose Prior studies have compared unicompartmental knee arthroplasty (UKA) with high tibial osteotomy (HTO) sug-gesting that both procedures had good functional outcomes. But none had established the superiority of one of the two pro-cedures for patients with high expectation including return to impact sport. The aim of this study was to compare functional outcomes and ability to return to impact sport of active patients defined with a pre-arthritis University of California and Los Angeles activity (UCLA) score $>8$, after UKA or HTO procedures.

Methods A retrospective review of patients with a pre-arthritis UCLA score $>8$ operated between January 2014 and September 2017 has identified 91 patients with open-wedge HTO and 117 patients with UKA. A matching process based on age ( \pm 3 years) and gender allowed to include 50 patients in each group for comparative analysis. Patient reported outcomes included Knee Osteoarthritis Outcomes Score (KOOS), UCLA Score, Knee Society Score (KSS) and time to return to sport or previous professional activities at 3,6,12 and 24 months following surgery.

Results Mean time to return to sport activities or previous professional activities were significantly lower for the HTO group than for UKA group [respectively, $4.9 \pm 2.2$ months for HTO group vs $5.8 \pm 6.2$ months for UKA group $(p=$ $0.006)$ and $3 \pm 3$ months for HTO group vs $4 \pm 3$ months for UKA group $(p=0.006)]$. At 24-month follow-up, UCLA score, KOOS Sports Sub-score and KSS activity score were significantly higher for HTO group than for UKA group $(\Delta: 2$ CI 95\% (1.3-2.5 points) $p<0.0001,(\Delta: 10.9$ CI 95\% (2.9-18.9 points) $p=0.04$ and $\Delta: 7.8$ CI 95\% (2.4-13.4 points) $p=$ 0.006 , respectively) and 31 patients (62\%) were practicing impact sport in the HTO group versus $14(28 \%)$ in the UKA group (odd-ratio 4.2 CI 95\% (1.8-9.7) $p<0.0001)$.

Conclusion HTO offers statistically significant quicker return to sport activities and previous professional activities with a higher rate of patients able to practice impact activity (62\% for HTO vs $28 \%$ for UKA) and better sports related functional scores at two years after surgery compared to UKA.

Level of evidence III retrospective case-control study.
\end{abstract}

Keywords Opening wedge high tibial osteotomy $\cdot$ Unicompartmental knee arthroplasty $\cdot$ Impact sport $\cdot$ Patient reported outcomes

Matthieu Ollivier

matthieu.ollivier@ap-hm.fr

1 Department of Orthopedics and Traumatology, St. Marguerite Hospital, Aix Marseille Univ, APHM, CNRS, ISM, Institute of Movement and Locomotion, 270 Boulevard Sainte Marguerite, BP 29, 13274 Marseille, France

2 International Knee and Joint Centre, PO Box 46705, Abu Dhabi, United Arab Emirates

\section{Introduction}

Treatment of knee osteoarthritis (OA) has become more challenging as surgeons are facing younger patients with higher expectation post-surgery 2 . In this group of patients, relief from pain is no longer the sole criteria for success but return to pre-disease level of activity is also important [1, 2]. For tricompartmental disease the decision making is reasonably straightforward with total knee arthroplasty (TKA) being the obvious choice with predictable outcome [3-5]. 
However, previous studies have demonstrated low proportion of patients are able to return to high impact activities $[6,7]$. Unicompartmental knee arthroplasty (UKA) might provide a better alternative in case of varus deformity with isolated medial compartment cartilage wear [8]. It is a less invasive procedure for a better range of motion (ROM), preservation of bone stock, maintenance of native biomechanics and quicker recovery time $[9,10]$.

High Tibial Osteotomy (HTO) represents an another alternative to UKA in case of extra-articular deformities leading to abnormal knee loading behavior and resultant intra-articular cartilage wear [11].

An essential advantage of both methods is that the anterior cruciate ligament remains intact and the proprioception is better than in the TKA $[12,13]$.

Unicompartmental knee arthroplasty (UKA) and high tibial osteotomy (HTO) are established treatment methods for moderate medial compartment OA, although choosing the appropriate surgical treatment for unicompartmental OA for patients with high expectation including return to impact sport remains somewhat controversial.[14-16].

Although the return to sport after HTO or UKA has already been analyzed [15, 17, 18], to date, no study of the literature have compared these two techniques in a specific population of patient practicing an impact sport before the onset of osteoarthritis symptoms.

The purpose of this study was to compare functional outcomes and ability to return to impact sport of active patients defined with a pre-arthritis University of California and Los Angeles activity score (UCLA) $>8$, after UKA or HTO procedures. We hypothesized that there is no difference between HTO and UKA with regard to recovery to sports and rate of patients returning to impact activities.

\section{Methods}

A retrospective comparative study identified 291 patients that underwent Medial UKA and 134 open-wedge HTO in our department between January 2014 and September 2017.

Indication for HTO included (HTO group): isolated medial knee osteoarthritis Ahlbäck grade $<3$ [19] with a preserved status of the patellofemoral and lateral tibio-femoral joints assessed using clinical and radiological (X-rays and MRI-scan) examination, a significant metaphyseal tibial vara (Medial plateau tibial angle $($ MPTA $)<84^{\circ}$ ), a stable knee in sagittal and coronal plane and the failure of all medical treatments.

Indication for UKA included (UKA group): isolated medial knee OA (Ahlbäck, any grade, see below) with a preserved status of the patellofemoral and lateral tibio-femoral joints assessed using clinical and radiological (X-rays and MRI-scan) examination, a stable knee in sagittal and coronal plane with range of knee movement from $0^{\circ}$ to at least $100^{\circ}$, a passively correctible varus on stress radiographs) and the failure of all medical treatments.

When both indications were possible the choice was left to the patient after clear information on the advantages and disadvantages of both techniques.

Exclusion criteria for both groups were: previous ipsilateral knee surgery (excluding knee arthroscopy for meniscal surgery), rheumatological disease process, as well as any contralateral and general co-morbidities restraining the overall mobility (e.g. neurological or neuromuscular conditions) and a follow-up of less than 2 years.

In order, to create comparable group of patients, patients with grade 1 of OA in the HTO group (7 patients) and grade 4 of OA in the UKA group (37 patients) were excluded. Finally, only grade 2 and 3 of OA in both groups were included in the study (Fig. 1).

After the analysis of the routine pre-operative questionnaire, only patients practicing an impact sport activity, as alpine ski, tennis/squash, jogging, soccer/football and martial arts, before the onset of arthritic symptoms (pre-arthritis UCLA score $>8$ ) were included (92 patients in HTO group and 119 patients in the UKA group).

A matching process based on age ( \pm 3 years) and gender allowed to finally include 50 patients in each group for comparative analysis.

Three different periods were compared. The pre-arthritis period corresponding to the period before arthrosis symptoms reported by patients. The preoperative period defined by status right before surgery. The postoperative period described the condition at the last follow-up (consultation or questionnaire if data were missing).

Both groups were comparable for demographic parameters and preoperative KOOS scores (Table 1). The mean time between onset of symptoms and knee surgery was $15 \pm 8$ [10-28] (HTO) and 19 \pm 9 [9-27] months (UKA) $(p=0.1)$. Mean age was 49.3 \pm 3.9 [44-54] and 50.8 \pm 4.4 [47-57] for HTO and UKA groups, respectively. Mean follow-up period was $3.7 \pm 1.6[2-5.5]$ years (HTO) and $3.9 \pm 1.8$ [2-5.7] years (UKA). $11 \mathrm{HTO}$ and 9 UKA $(p=0.5)$ patients had a pre-operative UCLA score $>8$. Only preoperative difference between groups was hip-knee-ankle angle (HKA), since the indication for HTO is significant varus malalignment when UKA doesn't have the goal to interfere with HKA (Table 1). Patients' labor load was similar between the groups (Table 2).

\section{Surgical procedure}

In the UKA group, a cemented medial UKA (ZUK LIMACorporate Undine) was implanted [20].

In the HTO group, the planned correction was calculated by the surgeon using conventional radiographs (weight 
Fig. 1 Patient flow chart. HTO high tibial osteotomy, UKA unicompartmental knee arthroplasty, OA Grade Osteoarthritis Ahlbäck grade

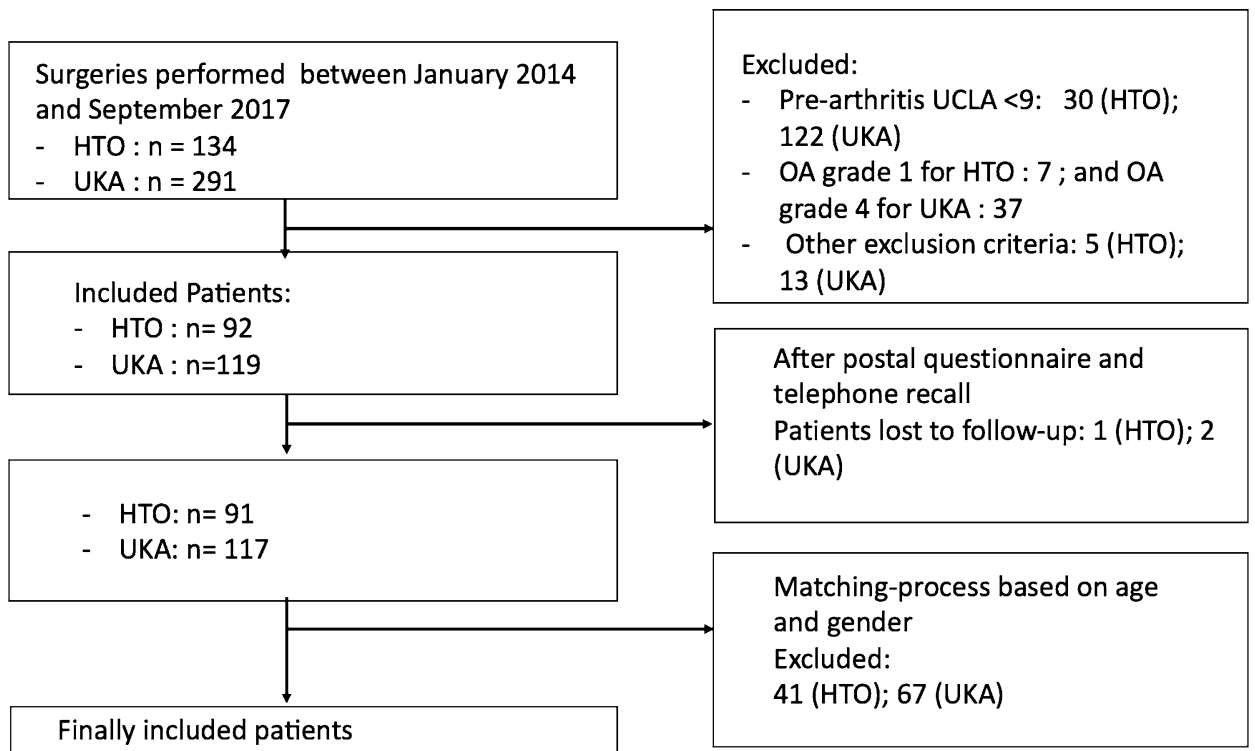

Table 1 Patient's characteristics

\begin{tabular}{|c|c|c|c|}
\hline Parameters & HTO $(n=50) \pm$ SD [range] & UKA $(n=50) \pm \mathrm{SD}$ [range] & $p$ value \\
\hline Mean age (years) & $49.3 \pm 3.9[44-54]$ & $50.8 \pm 4.4[47-57]$ & 0.3 \\
\hline Mean body mass index $\left(\mathrm{kg} / \mathrm{m}^{2}\right)$ & $26.6 \pm 2.6[19.3-29.9]$ & $27.1 \pm 3.1[20.1-31.2]$ & 0.2 \\
\hline Mean follow-up (years) & $3.7 \pm 1.6[2-5.5 .5]$ & $3.9 \pm 1.8[2-5.7]$ & 0.6 \\
\hline Gender (male) $(n)$ & 28 & 29 & 0.7 \\
\hline Mean pre-arthritis UCLA score & $9.2 \pm 0.5[9-10]$ & $9.4 \pm 0.4[9-10]$ & 0.2 \\
\hline Mean pre-operative UCLA score & $6.9 \pm 1.2[4-10]$ & $6.8 \pm 2[3-10]$ & 0.7 \\
\hline Mean preoperative KOOS Pain & $53 \pm 16[10-70]$ & $53 \pm 15[18-70]$ & 0.8 \\
\hline Mean preoperative KOOS Symptom & $47 \pm 19[10-70]$ & $51 \pm 17[10-70]$ & 0.2 \\
\hline Mean preoperative KOOS ADL & $47 \pm 18[5-70]$ & $50 \pm 17[8-64]$ & 0.3 \\
\hline Mean preoperative KOOS Sport & $37 \pm 19[7.5-65]$ & $41 \pm 21[7.5-70]$ & 0.4 \\
\hline Mean preoperative KOOS QQL & $44 \pm 13[8-70]$ & $47 \pm 15[8-70]$ & 0.3 \\
\hline $\begin{array}{l}\text { Mean time between onset of symptoms and } \\
\text { knee surgery }\end{array}$ & $15 \pm 8[10-28]$ & $19 \pm 9[9-27]$ & 0.1 \\
\hline Mean preoperative $\operatorname{HKA}\left({ }^{\circ}\right)$ & $171.5 \pm 4.2[165-175.5]$ & $176.0 \pm 0.3[175-178]$ & $<0.0001^{*}$ \\
\hline Mean postoperative HKA $\left(^{\circ}\right)$ & $181.6 \pm 1.1[176-184]$ & $178.4 \pm 0.2[177-180]$ & $<0.0001 *$ \\
\hline
\end{tabular}

HTO high tibial osteotomy, UKA unicompartmental knee arthroplasty, SD standard deviation, KOOS knee injury and osteoarthritis outcome score, $A D L$ activity of daily life, $Q O L$ quality of life, hip-knee-ankle angle (HKA)

*Statistically significant

Table 2 Labor load of patients

\begin{tabular}{lllllll}
\hline Parameters & Sitting & $\begin{array}{l}\text { Standing with- } \\
\text { out labor }\end{array}$ & $\begin{array}{l}\text { Standing with } \\
\text { some labor }\end{array}$ & Heavy labor & Total $(n)$ & $p$ value \\
\hline HTO $(n)$ & 14 & 8 & 14 & 14 & 50 & 0.2 \\
UKA $(n)$ & 15 & 11 & 11 & 13 & 50 & \\
\hline
\end{tabular}

HTO high tibial osteotomy, UKA unicompartmental knee arthroplasty 
bearing long-leg, $\mathrm{A} / \mathrm{P}$ and lateral views) following Miniaci's Method [21]. Subsequently all patients underwent a CT-scan and a Patient Specific Cutting Guide was designed to achieve the osteotomy following a previously published surgeon guided step-by-step procedure [22]. The bone defect was filled with femoral head wedge allograft in every patient. All the osteotomies were stabilized with the same implant (locking screw plate: New-clip Technics, Haute-Goulaine, France). All procedures were performed by two senior surgeons of our institution using the same previously described technique [23].

The same peri-operative protocol and postoperative regimen was used in both the groups, including full weight bearing as tolerated and heparin thromboprophylaxis for 30 days. There was no restriction on the patients to go back to impact activities postoperatively either after UKA or HTO. Concerning lateral hinge fractures for the HTO group:

For Takeuchi [24] Type 1 and 2 diagnosed intraoperatively; toe touch weight bearing for 6 weeks aided with the use of crutches was recommended. Full weight-bearing was allowed after 6 weeks.

For Takeuchi 3 diagnosed intraoperatively: the fracture was treated intraoperatively by two additional compression screw and no weight bearing during 6 weeks followed by toe touch weight bearing for 6 weeks aided with the use of crutches was recommended. Full weight-bearing was allowed after 12 weeks.

If hinge fractures was diagnosed at 6 weeks' follow-up, for the type I and 2, full weight bearing was extended. For the type III a toe touch weight bearing for 6 weeks was recommended before full weight bearing.

\section{Clinical follow-up}

Patients were evaluated at 4 weeks, 3 months, 6 months, 12 months and subsequently at every 12 months. Evaluation included radiographic imaging (AP and lateral views) and assessing complications, if any. Patient reported outcome scores were evaluated at every clinical visit, which included Knee Osteoarthritis Outcomes Score (KOOS), UCLA Activity Score (UCLA), Knee Society Score (KSS) and time to return to sport or previous professional activities [4, 25, 26]. If data were missing, a questionnaire was sent by post ( $n=17 ; 6$ for the HTO group and 11 for the UKA group) and any subsequent telephone recalls $(n=7 ; 4$ for HTO group and 3 for the UKA group) were performed in cases of nonreturn of the postal questionnaire. One patient in the HTO group and two patients in the UKA group were considered finally lost to follow-up because of missing data (Fig. 1).

Local Ethical Committee approval was obtained prior to study's initiation (Comité Informatique et Liberté (CIL)/ Assistance Publique des Hopitaux de Marseille (AP-HM)/ Registration Number 2019-17-03)).

\section{Statistical analysis}

Prior to initiation of the study, a power calculation was done to estimate the sample size in both the groups to have the $\mathrm{pB}$ at 0.8 . It was established, 50 patients in each group were needed to distinguish any difference, superior to the published minimal clinically important difference of the KOOS score [27]. The study was powered to $80 \%$ to detect a difference $>10$ points on the KSS or KOOS with a $p<0.05$ level. Data were represented as mean values with standard deviations and [ranges]. Normal (Gaussian) distributions was verified to determine adequate statistical testing method (Student $t$ tests vs Wilcoxon-Mann-Whitney tests) to estimate difference between groups in an univariate analysis. Multiple linear regression models were developed to establish the determinants for each of the variables. For each model, variables with a $p$ value less than 0.1 were kept in the final model.

Statistical analyses were performed with use of SSPS software (IBM; Armonk, NY).

\section{Results}

Mean time to return to sport activities (whatever sporting level) and previous professional activities were significantly lower for the HTO group than for UKA group [respectively, $4.9 \pm 2.2$ [2-9] months for HTO group vs $5.8 \pm 4.2$ [2-13] months for UKA group $(p=0.006)$ and $3.0 \pm 3.0$ [2-7] months for HTO group vs $4.0 \pm 3.0$ [2-13] months for UKA group $(p=0.006)]$.

24 months after surgery, 31 patients (62\%) were practicing impact sport in the HTO group vs 14 (28\%) in the UKA group (odd-ratio 4.2 CI 95\% (1.8-9.7) $p<0.001)$.

The mean UCLA score improvement from pre-operative to postoperative (at 24 months) period was significantly superior in the HTO group than in UKA group $(1.5 \pm 1.9$ vs $0.3 \pm 2.1 p<0.001)$.

The mean UCLA score deterioration from pre-arthritis to postoperative period (24 months) was significantly lower in the HTO group than in UKA group $(-0.3 \pm 2.1$ vs $-3.0 \pm 2.0 p<0.001)$.

At 2-year follow-up, mean UCLA score, KOOS Sports Sub-score and KSS activity score were significantly higher for HTO group ( $\Delta: 2$ CI $95 \%$ (1.3-2.5 points) $p<0.001,(\Delta$ : 10.9 CI $95 \%$ (2.9-18.9 points) $p=0.04$ and $\Delta: 7.8$ CI 95\% (2.4-13.4 points) $p=0.006$, respectively).

Patient reported outcome scores are summarized in Tables 3 and 4.

Multivariate analysis demonstrated that patients age significantly influenced the improvement of KOOS sports score $(p=0.01)$. Postoperative UCLA score was found to be influenced by the pre-arthritis value $(p=0.04)$. 
Table 3 Patients' postoperative sports and functional outcomes

\begin{tabular}{lccc}
\hline Parameters & HTO \pm SD [range] & UKA \pm SD [range] & $p$ value \\
\hline $\begin{array}{l}\text { Mean time to return to previous professional } \\
\text { occupation (months) }\end{array}$ & $3 \pm 3.0[2-7]$ & $4 \pm 3.0[2-13]$ & $0.006^{*}$ \\
Mean time to return to sport activities (months) & $4.9 \pm 2.2[2-9]$ & $5.8 \pm 4.2[2-13]$ & $0.006^{*}$ \\
Mean postoperative UCLA score & $8.4 \pm 1.6[6-10]$ & $6.5 \pm 2[3-10]$ & $<0.0001^{* \circ}$ \\
Mean KSS symptom at 24 months & $19 \pm 5.4[4-25]$ & $20 \pm 6.8[4-25]$ & 0.3 \\
Mean KSS satisfaction at 24 months & $33 \pm 6[10-40]$ & $30 \pm 8[2-40]$ & $0.04^{*}$ \\
Mean KSS expectation at 24 months & $8 \pm 1.7[3-14]$ & $9 \pm 2.4[3-14]$ & 0.3 \\
Mean KSS activity at 24 months & $84 \pm 8[62-100]$ & $75 \pm 9[46-96]$ & $0.006^{* \circ}$ \\
Mean KSS subtotal at 24 months & $61 \pm 7[44-78]$ & $60 \pm 9[40-78]$ & 0.6 \\
\hline
\end{tabular}

HTO high tibial osteotomy, UKA unicompartmental knee arthroplasty, UCLA University of California Los Angeles, KSS Knee Society Score

*Statistically significant

${ }^{\circ}$ Reaching minimal clinically important difference
Table 4 Patient reported outcome scores at 3, 6, 12 and 24 months

\begin{tabular}{|c|c|c|c|c|}
\hline Parameters & Time (months) & HTO & UKA & $p$ value \\
\hline \multicolumn{5}{|l|}{ KOOS } \\
\hline QOL & 3 & $63 \pm 6$ & $60 \pm 7$ & 0.3 \\
\hline Sports & & $47 \pm 7$ & $47 \pm 8$ & 0.8 \\
\hline ADL & & $67 \pm 6$ & $67 \pm 9$ & 0.5 \\
\hline Symptom & & $68 \pm 9$ & $67 \pm 8$ & 0.6 \\
\hline Pain & & $72 \pm 7$ & $71 \pm 9$ & 0.3 \\
\hline VAS & & $2.9 \pm 2$ & $2.9 \pm 3$ & 0.9 \\
\hline \multicolumn{5}{|l|}{ KOOS } \\
\hline QOL & 6 & $72 \pm 6$ & $69 \pm 8$ & 0.5 \\
\hline Sports & & $67 \pm 6$ & $56 \pm 7$ & $0.03 * \circ$ \\
\hline ADL & & $76 \pm 7$ & $77 \pm 8$ & 0.5 \\
\hline Symptom & & $76.8 \pm 9$ & $76.3 \pm 7$ & 0.6 \\
\hline Pain & & $81.1 \pm 6$ & $80.5 \pm 7$ & 0.4 \\
\hline VAS & & $2.3 \pm 2$ & $1.9 \pm 3$ & 0.2 \\
\hline \multicolumn{5}{|l|}{ KOOS } \\
\hline QOL & 12 & $79 \pm 8$ & $76 \pm 7$ & 0.5 \\
\hline Sports & & $74 \pm 7$ & $63 \pm 6$ & $0.01 * \circ$ \\
\hline ADL & & $84 \pm 8$ & $84 \pm 7$ & 0.4 \\
\hline Symptom & & $84 \pm 7$ & $83 \pm 8$ & 0.8 \\
\hline Pain & & $88 \pm 8$ & $87 \pm 7$ & 0.8 \\
\hline VAS & & $1.7 \pm 1.2$ & $1.5 \pm 0.8$ & 0.2 \\
\hline \multicolumn{5}{|l|}{ KOOS } \\
\hline QOL & 24 & $81 \pm 7$ & $78 \pm 7$ & 0.5 \\
\hline Sports & & $76 \pm 6$ & $65 \pm 7$ & $0.009 * \circ$ \\
\hline $\mathrm{ADL}$ & & $84 \pm 7$ & $84 \pm 6$ & 0.9 \\
\hline Symptom & & $86 \pm 8$ & $86 \pm 9$ & 0.6 \\
\hline Pain & & $91 \pm 9$ & $91 \pm 10$ & 0.7 \\
\hline VAS & & $1.0 \pm 0.5$ & $0.9 \pm 0.4$ & 0.5 \\
\hline
\end{tabular}

HTO high tibial osteotomy, UKA unicompartmental knee arthroplasty, KOOS knee injury and osteoarthritis outcome score, QOL quality of life, $A D L$ activity of daily life

*Statistically significant

${ }^{\circ}$ Reaching minimal clinically important difference
Concerning complications, for the HTO group $16.7 \%$ patients were found to have lateral hinge fractures $(83.3 \%$ type $1,8.3 \%$ type 2 and $8.3 \%$ type 3 ). One nonunion was seen at 9 months after HTO, union was achieved 5 months after a revision procedure.

No infection was observed in both groups (UKA and HTO).

No patients had a UKA revision or HTO conversion to UKA/TKA during follow-up, 11 (22\%) patients from the HTO group underwent hardware removal at a mean followup of 18.1 \pm 4.4 [10-29] months.

\section{Discussion}

The most important finding of the present study was that HTO offers statistically significant quicker return to sport activities and previous professional activities with a higher rate of patients able to practice impact activity ( $62 \%$ for HTO vs $28 \%$ for UKA) and better sports related functional scores at two years after surgery compared to UKA in a population of active patients defined with a pre-arthritis University of California and Los Angeles activity score (UCLA) $>8$. The hypothesis that both procedures were similar for returning to impact sports was not verified in this study.

While both procedures are often realized in a very similar population (in terms of demographic parameters), their aims are deeply different: HTO intends to correct extra-articular deformities leading to abnormal knee loading and resultant intra-articular cartilage wear [11], while UKA aims solely to resurface a worn tibiofemoral compartment leaving lower-limb mechanical axis in its preoperative configuration. Traditionally, UKA was indicated for patients aged over 60 years old with unicompartimental OA without a high activity level [28] while HTO was indicated for younger 
patients ( $<60$ years old) with varus malalignment and moderate unicompartimental arthrosis [29].

The surgical indications for UKA have expanded because of improved surgical techniques and modern implant designs, along with increased experience with the procedure [30] allowing to use UKA for younger active people. Some of the indications for HTO and UKA may currently be similar in some cases [14], but choosing the appropriate surgical treatment for unicompartmental OA for patients with sports expectations remains somewhat controversial [14-16].

Several studies and meta-analysis are available in the literature comparing clinical outcomes of HTO and UKA, some of them including results about sports activities (Table 5) [15, 23, 31-33]. But the difference in population between the different studies, in particular on the age and

Table 5 Literature review of recent studies comparing HTO and UKA sports recovery

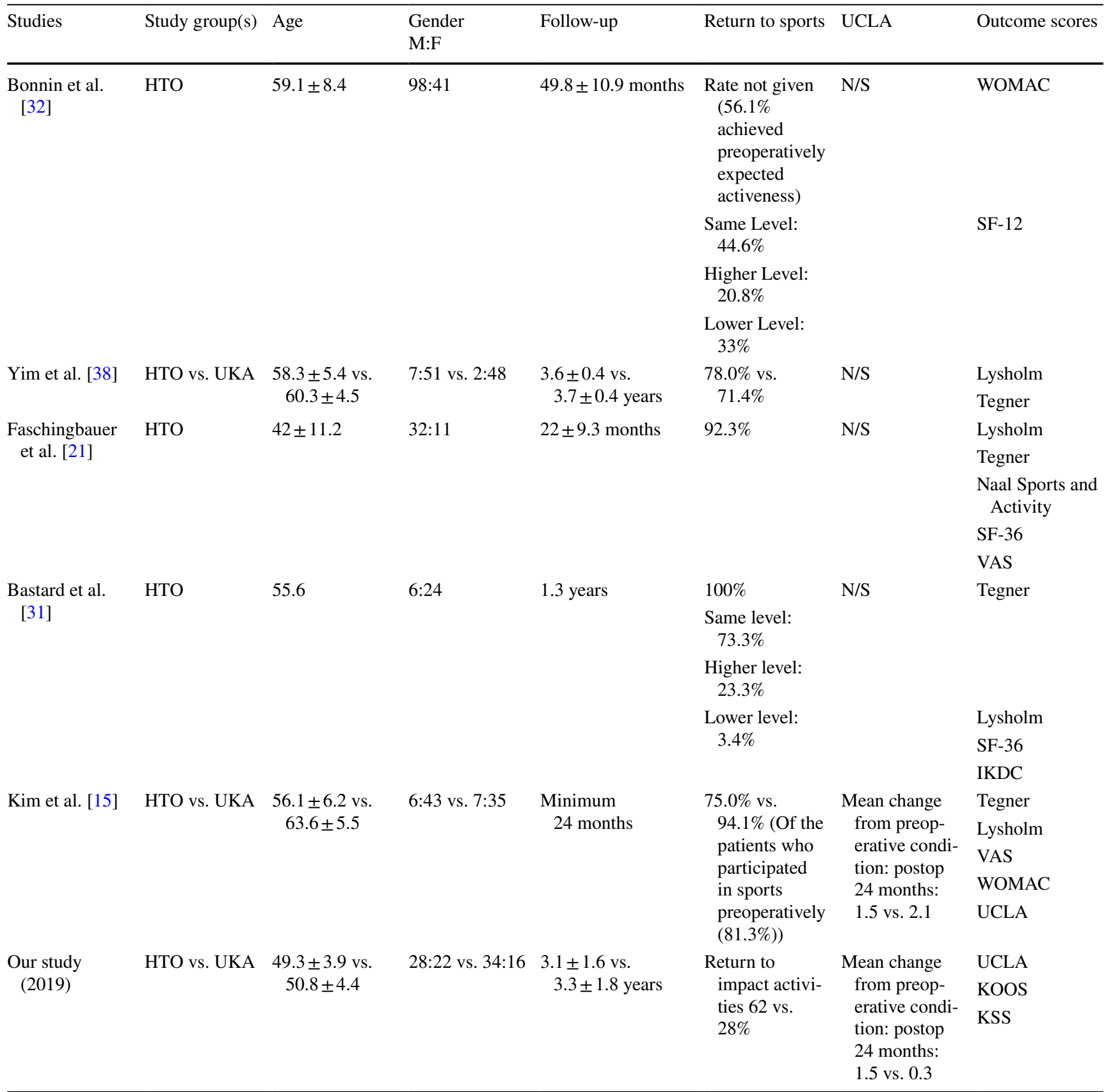

HTO high tibial osteotomy, UKA unicompartmental knee arthroplasty, KOOS knee injury and osteoarthritis outcome score, UCLA University of California Los Angeles, KSS knee society score, VAS visual analogue scale, WOMACWestern Ontario and McMaster Universities Osteoarthritis Index, $S F$ short form, IKDC international knee documentation committee, $M$ male, $F$ female, Postop postoperative 
level of sport activity, but also the differences in score used, complicated the comparison between the studies.

Kim et al. [15] reported a higher (75.0\% vs $94.1 \%)$ and quicker ( 8.4 vs 3.8 months) rate of return to sports activity in favor of UKA patients compared to HTO. The authors attributed this better outcome in the UKA group due to the ability of the procedure to remove the nociceptive stimulus from the medial compartment which was not possible in the joint preserving procedure of the HTO. The reason for the difference in the findings compared to this study lies probably in a less active population of patient in Kim et al., study. Indeed, nearly $20 \%$ of the patients in the study by Kim et al. [15] did not participate in any sporting activity in the pre-arthritis period and the mean pre-operative UCLA score for the HTO group was approximately 4 (6.9 in the present study) and 3 (6.8 in the present study) for the UKA group. Also, authors in the study of Kim et al., stated that most patients followed their recommendations to avoid high-impact sports activities after the operation, which could negatively impact their results.

The findings in the present study are in accordance with the paper of Bastard et al. [31] who observed that all of their 30 patients treated with HTO returned to sports at 1 year with $7(23.3 \%)$ of them returning at a higher level than before the procedure. A systematic review by Ekhtiari et al. [34] reported similar findings regarding HTO procedure that $85 \%$ of the 216 patients returning to a level of sport similar or better than pre-operatively.

A recent study [35] indicated that sustained sports participation in the year before surgery is one of the most important prognostic factors for returning to sports after HTO. This was the case in this study as all patients returned to sports whatever the level of impact in both groups. However, at 2 years of follow up $62 \%$ of HTO patients and only $28 \%$ in the UKA group were still involved in impact activities. Studies have observed this shift from high to low impact activity level after UKA or HTO [17, 18, 23], potentially influenced by a variety of factors like physical and mental conditioning, patient motivation, pain or surgeon's advice.

Comparing the UCLA scores, the HTO group improved their scores to almost the pre-arthritis levels (pre-arthritis $9.2 \pm 0.1$ to postoperative $8.4 \pm 0.2$ ), whereas there was a drop in the UCLA scores compared to pre-arthritis values for the UKA group $(9.4 \pm 0.1$ to $6.5 \pm 0.2)$.

These results suggest that in addition to the lower rate of patient practicing an impact sport after UKA compared to those after HTO, the level of sport intensity is also lower after UKA than after HTO. This also suggests that operating the impact sport patients at an earlier stage of osteoarthritis with HTO gives them a better chance to recover a sport level similar or close to the one they had before the onset of arthritis.
KOOS sports score improvement was significantly better for the HTO group and age at the time of surgery was found to be an important factor influencing the improvement in all patients. The KSS score was significantly better for the HTO group at 2 years, different from the findings of Cho et al. [36] who reported better outcomes for the UKA group or those of Takeuchi et al. [37] who found no difference between HTO and UKA groups. This difference can be explained by an older population of patient (mean age 67 years old for the HTO group and 77 years old for the UKA group) and the absence of inclusion criteria related to the level of sports activity.

There are several limitations in the present study that must be appreciated when interpreting these findings. Firstly, data collection was done in a retrospective manner, but despite this, matched groups for both treatment modalities were created. The groups were carefully matched for demographic parameters (age and gender). Due to the matching process for age, a substantial number of younger patients who underwent an HTO were excluded to avoid bias outcome against the UKA group.

Secondly, despite the small size sample, in both groups the power calculation was based on the $\mathrm{pB}$ set at 0.8 to minimize the type II error. The follow up was set at 2 years as the purpose of the study was only to evaluate the ability to return to impact sports after UKA or HTO surgery.

Thirdly, this is a two surgeons series and there might be an element of bias due to the post-operative regimen and advice. However, the post-operative protocols were similar between the surgeons and there was no restriction on the patients to go back to impact activities postoperatively either after UKA or HTO.

Fourth, these results cannot be generalized for all cases of sports patients with unicompartmental OA. HTO does not solve the problem of severe cartilage diseases (Ahlbäck grade $>3$ ) and in this situation the use of a UKA represents the only surgical therapeutic solution. To build comparable groups in term of preoperative degenerative changes, patients suffering from early and end stages of arthritis were excluded from the final analyses, having those patients included would have created important recruitment bias with more affected joints in the UKA than in HTO group.

Finally, while the most common reason for knee surgery in osteoarthritic patients was improved functioning [38], this study did not evaluate specifically patient's expectation concerning the return to the same level of sport. But this is the only study in the literature that focuses on an active population of patients practicing an impact sport before the onset of osteoarthritis symptoms. The relatively short time between surgery and the onset of symptoms $(15 \pm 8$ [10-28] months for HTO and 19 \pm 9 [9-27] months for UKA group) suggests that these patients wanted to return to an equivalent function. 
Despite these limits, the results of this study confirm the superior results of HTO compared to UKA in patients practicing impact sports before the onset of arthritic symptoms according to the indications of the two procedures. These results also suggest that operating the high impact sport patients at an earlier stage of osteoarthritis with HTO gives them a better chance to recover a sport level similar or close to the one they had before the onset of arthritis.

\section{Conclusion}

HTO offers statistically significant quicker return to sport activities and previous professional activities with a higher rate of patients able to practice impact activity (62\% for HTO vs $28 \%$ for UKA) and better sports related functional scores at two years after surgery compared to UKA.

Author contributions CJ and FG have made substantial contributions to acquisition of data, or analysis and interpretation of data. AP, AS, JNA, and SP have been involved in drafting the manuscript or revising it critically. MO has made substantial contributions to conception and design, or acquisition of data, or analysis and interpretation of data. Every authors have given final approval of the version to be published and agree to be accountable for all aspects of the work in ensuring that questions related to the accuracy or integrity of any part of the work are appropriately investigated and resolved.

Funding No funding was required for this study.

\section{Compliance with ethical standards}

Conflict of interest Local ethic committee approved our study protocol prior to investigation. Some of the authors disclosed potential conflict of interest.

Ethical approval Local Ethical Committee approval was obtained prior to study's initiation (Comité Informatique et Liberté (CIL)/Assistance Publique des Hopitaux de Marseille (APHM)/ Registration Number 2019-17-03))

\section{References}

1. Kurtz SM, Lau E, Ong K, Zhao K, Kelly M, Bozic KJ (2009) Future young patient demand for primary and revision joint replacement: national projections from 2010 to 2030. Clin Orthop Relat Res 467:2606-2612

2. Losina E, Thornhill TS, Rome BN, Wright J, Katz JN (2012) The dramatic increase in total knee replacement utilization rates in the United States cannot be fully explained by growth in population size and the obesity epidemic. J Bone Jt Surg Am 94:201-207

3. Lyons MC, MacDonald SJ, Somerville LE, Naudie DD, McCalden RW (2012) Unicompartmental versus total knee arthroplasty database analysis: is there a winner? Clin Orthop Relat Res 470:84-90
4. Scuderi GR, Bourne RB, Noble PC, Benjamin JB, Lonner JH, Scott WN (2012) The new knee society knee scoring system. Clin Orthop 470:3-19

5. Dahl WA, Robertsson O, Lidgren L (2010) Surgery for knee osteoarthritis in younger patients. Acta Orthop 81:161-164

6. Schmalzried TP, Shepherd EF, Dorey FJ, Jackson WO, Rosa M, Favae F, McKellop HA, McClung CD, Martell J, Moreland JR, Amstutz HC (2000) The John Charnley Award Wear is a function of use, not time. Clin Orthop 2000:36-46

7. Witjes S, Gouttebarge V, Kuijer PPFM, Van GRCI, Poolman RW, Kerkhoffs GMMJ (2016) Return to sports and physical activity after total and unicondylar knee arthroplasty: a systematic review and meta-analysis. Sports Med 46:269-292

8. Berend KR, Berend ME, Dalury DF, Argenson J-N, Dodd CA, Scott RD (2015) Consensus statement on indications and contraindications for medial unicompartmental knee arthroplasty. J Surg Orthop Adv 24:252-256

9. Kleeblad LJ, van der List JP, Zuiderbaan HA, Pearle AD (2018) Larger range of motion and increased return to activity, but higher revision rates following unicompartmental versus total knee arthroplasty in patients under 65: a systematic review. Knee Surg Sports Traumatol Arthrosc 26:1811-1822

10. Naal FD, Fischer M, Preuss A, Goldhahn J, von Knoch F, Preiss S, Munzinger U, Drobny T (2007) Return to sports and recreational activity after unicompartmental knee arthroplasty. Am J Sports Med 35:1688-1695

11. Brinkman J-M, Lobenhoffer P, Agneskirchner JD, Staubli AE, Wymenga AB, van Heerwaarden RJ (2008) Osteotomies around the knee. J Bone Jt Surg Br 90:1548-1557

12. Bragonzoni L, Rovini E, Barone G, Cavallo F, Zaffagnini S, Benedetti MG (2019) How proprioception changes before and after total knee arthroplasty: a systematic review. Gait Posture 72:1-11

13. Wautier D, Thienpont E (2017) Changes in anteroposterior stability and proprioception after different types of knee arthroplasty. Knee Surg Sports Traumatol Arthrosc 25:1792-1800

14. Cao Z, Mai X, Wang J, Feng E, Huang Y (2018) Unicompartmental knee arthroplasty vs high tibial osteotomy for knee osteoarthritis: a systematic review and meta-analysis. J Arthroplasty 33:952-959

15. Kim MS, Koh IJ, Sohn S, Jeong JH, In Y (2018) Unicompartmental knee arthroplasty is superior to high tibial osteotomy in postoperative recovery and participation in recreational and sports activities. Int Orthop 43:2493-2501

16. Mancuso F, Hamilton TW, Kumar V, Murray DW, Pandit H (2016) Clinical outcome after UKA and HTO in ACL deficiency: a systematic review. Knee Surg Sports Traumatol Arthrosc 24:112-122

17. Hoorntje A, Witjes S, Kuijer PPFM, Koenraadt KLM, van Geenen RCI, Daams JG, Getgood A, Kerkhoffs GMMJ (2017) High rates of return to sports activities and work after osteotomies around the knee: a systematic review and meta-analysis. Sports Med 47:2219-2244

18. Waldstein W, Kolbitsch P, Koller U, Boettner F, Windhager R (2017) Sport and physical activity following unicompartmental knee arthroplasty: a systematic review. Knee Surg Sports Traumatol Arthrosc 25:717-728

19. Ahlbäck S (1968) Osteoarthrosis of the knee. A radiographic investigation. Acta Radiol Diagn Suppl 277:7-72

20. Argenson J-NA, Parratte S, Flecher X, Aubaniac J-M (2007) Unicompartmental knee arthroplasty: technique through a miniincision. Clin Orthop 464:32-36

21. Elson DW, Petheram TG, Dawson MJ (2015) High reliability in digital planning of medial opening wedge high tibial osteotomy, using Miniaci's method. Knee Surg Sports Traumatol Arthrosc 23:2041-2048

22. Munier M, Donnez M, Ollivier M, Flecher X, Chabrand P, Argenson JN, Parratte S (2017) Can three-dimensional patient-specific 
cutting guides be used to achieve optimal correction for high tibial osteotomy? Pilot study. Orthop Traumatol Surg Res 103:245-250

23. Faschingbauer M, Nelitz M, Urlaub S, Reichel H, Dornacher D (2015) Return to work and sporting activities after high tibial osteotomy. Int Orthop 39:1527-1534

24. Takeuchi R, Ishikawa H, Kumagai K, Yamaguchi Y, Chiba N, Akamatsu Y, Saito T (2012) Fractures around the lateral cortical hinge after a medial opening-wedge high tibial osteotomy: a new classification of lateral hinge fracture. J Arthrosc Relat Surg 28:85-94

25. Ornetti P, Parratte S, Gossec L, Tavernier C, Argenson J-N, Roos EM, Guillemin F, Maillefert JF (2008) Cross-cultural adaptation and validation of the French version of the Knee injury and Osteoarthritis Outcome Score (KOOS) in knee osteoarthritis patients. Osteoarthr Cartil 16:423-428

26. Zahiri CA, Schmalzried TP, Szuszczewicz ES, Amstutz HC (1998) Assessing activity in joint replacement patients. J Arthroplasty 13:890-895

27. Roos EM, Lohmander LS (2003) The Knee injury and Osteoarthritis Outcome Score (KOOS): from joint injury to osteoarthritis. Health Qual Life Outcomes 1:1-8

28. Borus T, Thornhill T (2008) Unicompartmental knee arthroplasty. J Am Acad Orthop Surg 16:9-18

29. Zuiderbaan HA, van der List JP, Kleeblad LJ, Appelboom P, Kort NP, Pearle AD, Rademakers MV (2016) Modern indications, results, and global trends in the use of unicompartmental knee arthroplasty and high tibial osteotomy in the treatment of isolated medial compartment osteoarthritis. Am J Orthop 45:E355-E361

30. Pennington DW, Swienckowski JJ, Lutes WB, Drake GN (2003) Unicompartmental knee arthroplasty in patients sixty years of age or younger. J Bone Jt Surg Am 85:1968-1973

31. Bastard C, Mirouse G, Potage D, Silbert H, Roubineau F, Hernigou P, Flouzat-Lachaniette CH (2017) Return to sports and quality of life after high tibial osteotomy in patients under 60 years of age. Orthop Traumatol Surg 103:1189-1191
32. Bonnin MP, Laurent JR, Zadegan F, Badet R, Pooler Archbold HA, Servien E (2011) Can patients really participate in sport after high tibial osteotomy? Knee Surg Sports Traumatol Arthrosc 21:64-73

33. Yim JH, Song EK, Seo HY, Kim MS, Seon JK (2013) Comparison of high tibial osteotomy and unicompartmental knee arthroplasty at a minimum follow-up of 3 years. J Arthroplasty 28:243-247

34. Ekhtiari S, Haldane CE, De SD, Simunovic N, Musahl V, Ayeni OR (2016) Return to work and sport following high tibial osteotomy. J Bone Jt Surg Am 98:1568-1577

35. Hoorntje A, Kuijer PPFM, van Ginneken BT, Koenraadt KLM, van Geenen RCI, Kerkhoffs GMMJ, van Heerwaarden RJ (2019) Prognostic factors for return to sport after high tibial osteotomy: a directed acyclic graph approach. Am J Sports Med 47:1854-1862

36. Cho WJ, Kim JM, Kim WK, Kim DE, Kim NK, Il BS (2018) Mobile-bearing unicompartmental knee arthroplasty in old-aged patients demonstrates superior short-term clinical outcomes to open-wedge high tibial osteotomy in middle-aged patients with advanced isolated medial osteoarthritis. Int Orthop 42:2357-2363

37. Takeuchi R, Umemoto Y, Aratake M, Bito H, Saito I, Kumagai K, Sasaki Y, Akamatsu Y, Ishikawa H, Koshino T, Saito T (2010) A mid term comparison of open wedge high tibial osteotomy vs unicompartmental knee arthroplasty for medial compartment osteoarthritis of the knee. J Orthop Surg 5:1-8

38. Wiering B, de Boer D, Delnoij D (2018) Meeting patient expectations: patient expectations and recovery after hip or knee surgery. Musculoskelet Surg 102:231-240 